\title{
Epidemiology of traumatic spinal cord injury in Nepal: A systematic review
}

\author{
Bikash Parajuli', Khagendra Acharya ${ }^{2}$, Dipak Shrestha ${ }^{3}$ \\ ${ }^{1}$ Lecturer, Department of Orthopedics and Traumatology, Dhulikhel Hospital/ Kathmandu University Hospital, Kavre, \\ Nepal, ${ }^{2}$ Assistant Professor, Department of Management Informatics and Communication, Kathmandu University, \\ Kavre, Nepal, ${ }^{3}$ Professor, Department of Orthopedics and Traumatology, Dhulikhel Hospitall Kathmandu University \\ Hospital, Kavre, Nepal
}

\section{A B S T R A C T}

Spinal cord injury (SCI) leads to disabling condition. In Nepal the nationwide statistics of incidence and prevalence of $\mathrm{SCl}$ is still unclear which demands a systematic examination of crucial epidemiological aspects of SCl. An electronic search was conducted on PubMed, Ovid EMBASE, Cochrane Library and Google Scholar. Clinical studies investigating epidemiology of spinal cord injury were included. A narrative synthesis of the data that comprised 1796 patients was conducted. Males comprised $73 \%$, and the mean age varied from 32 to 47 years. The two leading causes of $\mathrm{SCl}$ were falls $(60 \%)$ and accidents $(17 \%)$. Most patients had incomplete neurology (AIS grade $B, C$ and $D=42 \%$ ) followed by AIS A grade $(36.3 \%$ ). Cervical injury (37.4\%) was the most common level of injury. Mortality during hospital stay was low $(1.98 \%)$ whereas after rehabilitation was high $(24.32 \%)$. The review contributes in understanding epidemiology of $\mathrm{SCl}$ in Nepal which is expected to help in planning for prevention and management.

Systematic Review Registration: PROSPERO CRD42019135301

Key words: Spinal cord injury; Epidemiology; Nepal; Systematic review
http://nepjol.info/index.php/AJMS DOI: 10.3126/ajms.v11i6.30151

E-ISSN: 2091-0576

P-ISSN: $2467-9100$

Copyright (c) 2020 Asian Journal of Medical Sciences

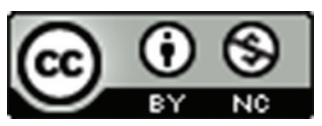

This work is licensed under a Creative Commons Attribution-NonCommercial 4.0 International License.

\section{INTRODUCTION}

Spinal cord injury (SCI) is associated with permanent disability and decreased life expectancy, ${ }^{1}$ with the incidence rate in developing countries ranging from 13.0 to 220.0 per million, and in developed countries varying from 13.1 to 163.4 per million. ${ }^{2}$ Worldwide prevalence is reported to be $1: 1000,{ }^{3}$ with huge difference in countrywise statistics - 906 per million in the US, ${ }^{4} 526$ per million in Iceland, ${ }^{5} 490$ to 886 per million in Australia ${ }^{6}$ and 15-20 per million in India.

Comprehensive information related to the epidemiology of SCI in many developing countries is yet to be available. Further, as curative treatment for SCI is barely available in these locations, applying preventive measures is an obligatory option to reduce SCI burden. ${ }^{8}$ In planning for preventive strategies, an initial undertaking is to investigate epidemiological pattern of SCI. ${ }^{9}$ However, as comprehensive data are not available, and the available findings of epidemiological studies from developed countries cannot be transported to a developing country like Nepal, ${ }^{10}$ there is a need to understand the epidemiological pattern of SCI. This systematic review aims to pool all the available data to better understand epidemiological patterns of SCI in Nepal.

\section{MATERIALS AND METHODS}

\section{Protocol development and registration}

This systematic review was initially registered in the International Prospective Register of Systematic 
Reviews (PROSPERO) with the registration number CRD42019135301. Preferred Reporting Items for Systematic Reviews and Meta-Analyses Protocol (PRISMA-P) guidelines was used to search relevant literature, determining inclusion and exclusion criteria, outcome measures and statistical analysis. The ethical approval for this research was not required because SCI patients were not involved in any aspect of this research.

\section{Search strategy}

Four databases, namely (a) PubMed (last search till April 2020), (b) Ovid EMBASE (1974 to latest issue; last search on April 2020), (c) Cochrane Library (last search till April 2020) and (d) Google Scholar (last search till April 2020) were searched. The first string during the search included Spine OR Spinal Injury OR Spinal cord injury OR Traumatic Spinal injury OR Spine Epidemiology; and the second string was Nepal. Truncated search terms and the "related articles" function was used to broaden the search. Additionally, the articles in the references of included studies were manually searched in order to identify any additional studies.

\section{Inclusion criteria}

All clinical studies involving epidemiology of spinal cord injury in Nepal that were published in English language were selected. However, the studies including patients below 16 years and the studies involving the same population were excluded from the review. Review articles, editorials, case reports, letters, conference abstracts, and unpublished studies were also excluded. Further, the studies based on interventions/ exposures in spinal cord injury patients were excluded (Figure 1).

\section{Outcome measures}

The main outcomes included patient demographics, etiology of SCI, severity distribution, spinal level, delays in hospital arrival, treatment modality and mortality of SCI patients in Nepal.

American Spinal Injury Association (ASIA) and Frankel grading were used to measure the severity of SCI. Delay in hospital arrival (time from trauma to hospital arrival) was measured in hours. Treatment modalities were broadly categorized as surgical and conservative treatment.

Two studies, namely, Lakhey et al. ${ }^{11}$ and Shrestha et al. ${ }^{12}$ were not included in this review because both were a part of the study by Bajracharya et al. ${ }^{13}$ that was carried out in BPKIHS, Dharan.

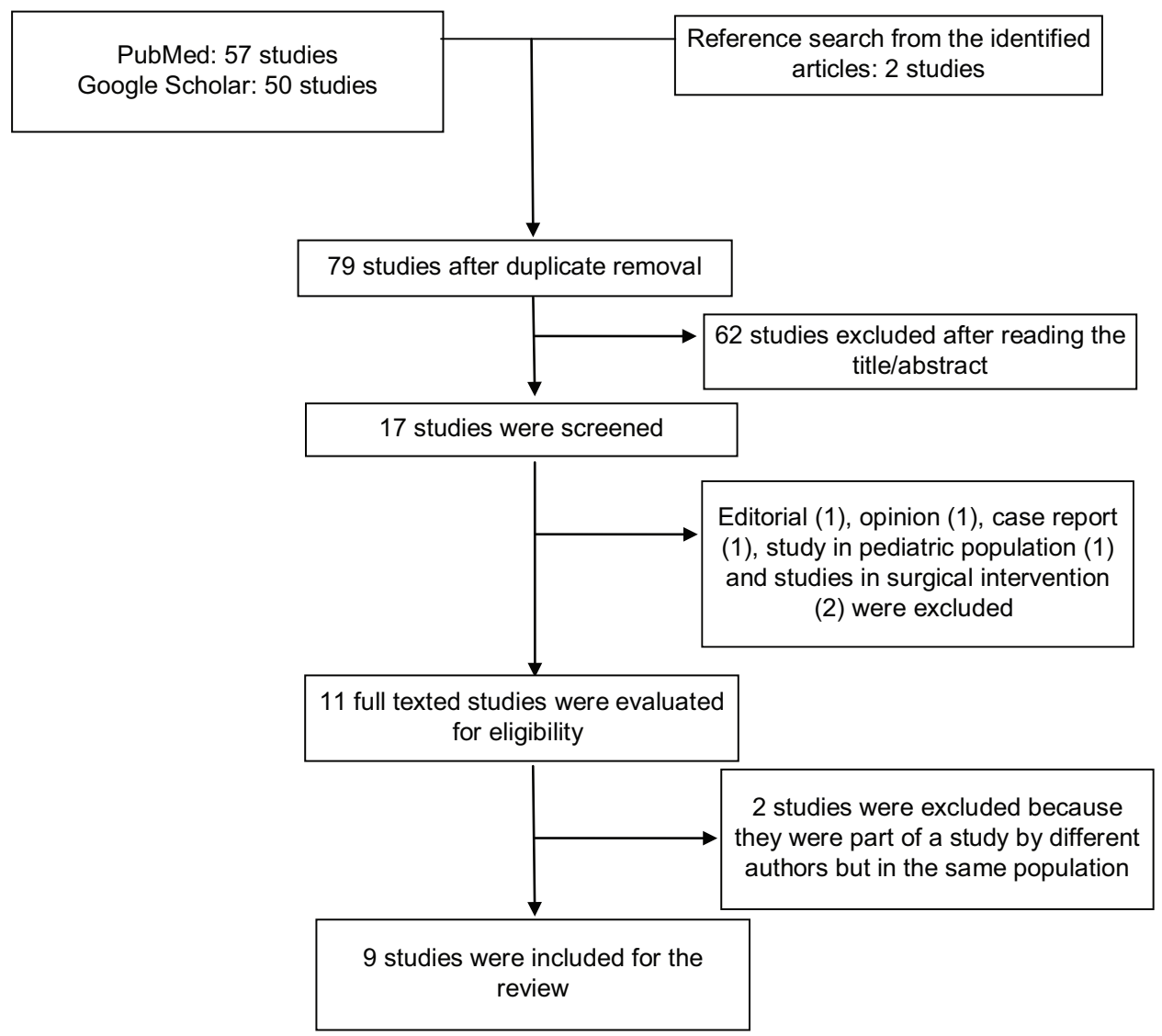

Figure 1: Flow diagram of literature selection process 


\section{Data extraction}

All the titles and/or abstracts of the studies obtained from search strategies were screened by two authors independently. The full texts of the potentially eligible studies were retrieved and independently assessed for eligibility by two authors. Any disagreement between the two authors was resolved through discussion with the third author.

Data were extracted in a customized form, contrary to the original plan to enter the required data in standard pro forma, as the extracted data did not fit the format. Two review authors extracted data independently; and discrepancies were identified and resolved through the discussion between the two and with the third author where necessary. Missing data were requested from the concerned authors ${ }^{14,15}$.

\section{Data synthesis and analysis}

A narrative synthesis of data from the selected studies was carried out in the following steps: a) studies were arranged into logical categories like study designs, outcomes etcetera.; b) within study analysis of data was done, and systematic tabulation of information from each study was taken; c) cross-study synthesis was done; and d) variations in study characteristics and study biases were addressed.

Descriptive statistics was used to analyze the demographic variables in the data. Statistical analysis was performed using IBM SPSS Statistics version 23 (Armonk, NY, USA). Means and standard deviations were used to summarize continuous measures, while categorical data were summarized with the use of counts and percentages. For the data that were diverse to combine, tabulated representation of the data from each study was done.

\section{Risk of bias}

The data supplied in the available studies was checked for their completeness and internal consistency. Attrition bias due to incomplete outcome data was addressed by contacting the corresponding authors of the respective studies. Independent double data extraction was done to avoid information bias.

\section{RESULTS}

\section{Types of studies and their properties}

Our search found 9 studies presenting SCI epidemiology: four were retrospective, 3 were prospective, one each was descriptive and prospective-cohort. (Table 1)

In terms of the setting, one study was done in BP Koirala Institute of Health Sciences (BPKIHS), Dharan; ${ }^{13}$ two in Spinal Injury Rehabilitation Centre (SIRC), Kavre; ${ }^{14,16}$ two in National Trauma Centre (NTC), Kathmandu; ${ }^{17,18}$ one in College of Medical Sciences (COMS) Chitwan; ${ }^{15}$ one in Green Pasture Hospital and Rehabilitation Centre (GPHRC), Pokhara; ${ }^{19}$ one in Gandaki Medical College (GMC), Pokhara; ${ }^{20}$ and one in Nobel Medical College (NMC), Biratnagar. ${ }^{21}$ None of them represent studies from the western part of Nepal. Cumulatively, these studies included 1796 SCI patients.

The population size of these studies ranged from 36 to 896 with an average of 245 patients per study. The study span ranged from May 1997 to October 2018; the shortest study covered the duration of 3 months and the longest was of 10 years.

\section{Demography: Gender and age}

Out of 1796 patients, $1315(73.2 \%)$ were male and $481(26.8 \%)$ were female with male to female ratio of $2.8: 1$. The study with the highest male population $(90 \%)$ was seen in the study by Dhakal et al. ${ }^{18}$ In the study of population who suffered spinal trauma after earthquake, however, the number of female was higher, accounting for $56 \%{ }^{14}$

The composite mean age of patient in all studies was 40 years with the mean age ranging from $32^{19}$ to 47.5 years. ${ }^{20}$ Age wise categorization was done only in 5 studies ${ }^{13-}$ ${ }^{16,21}$ which showed the maximum number of patients in $>50$ years and 21-30 age group category (371 and 365, respectively). (Figure 2)

\section{Etiology}

Two most common etiologies reported in the literature were falls (from tree, hill-slopes, and floors as well as ladders

\begin{tabular}{lllc} 
Table 1: Available literature on epidemiology of SCI in Nepal & & \\
\hline Study & Design & Site & Study Period \\
\hline Bajracharya et al., $2007^{13}$ & Retrospective & BPKIHS & $4 / 1996-5 / 2005$ \\
Scovil et al., $2012^{19}$ & Cohort & GPHRC & $2008-2009$ \\
Shrestha et al., $2013^{16}$ & Retrospective & SIRC & $1 / 2008-1 / 2011$ \\
Devkota et al., $2013^{20}$ & Retrospective & GMC & $10 / 2010-9 / 2011$ \\
Groves et al., $2017^{14}$ & Descriptive & SIRC & $4 / 2015-6 / 2016$ \\
Munakomi et al., $2017^{15}$ & Prospective cohort Observational & COMS & $3 / 2013-32016$ \\
Dhakal et al., $2018^{17}$ & Retrospective & NTC & 117 \\
Dhakal et al., $2019^{18}$ & Retrospective cohort & NTC & $12 / 2015-8 / 2017$ \\
Kafle et al., $2019^{21}$ & Prospective & NMC & $12 / 2015-8 / 2017$ \\
\hline
\end{tabular}

BPKIHS: B. P. Koirala Institute of Health Sciences, COMS: College of Medical Sciences, GMC: Gandaki Medical College, GPHRC: Green Pasture Hospital and Rehabilitation Centre, NMC: Nobel Medical College, NTC: National Trauma Centre, SIRC: Spinal Injury Rehabilitation Centre 
of house), and road traffic accidents (RTAs). A total of 1077 patients sustained fall injury followed by 305 patients sustaining road traffic accidents, 128 patients had burial injury, 76 patients had farm related injuries, and remaining 210 patients had other injuries. One study ${ }^{15}$ had RTA as the most common injury for traumatic spinal injury (51\%) and one study ${ }^{14}$ had burial as the major cause of traumatic spinal injury (84\%) (Table 2).

There were a total of $855(63 \%)$ patients with fall injury and $203(15 \%)$ patients with RTA in the studies done before 2017. However, in the studies done in and after 2017, the patients sustaining fall injury was $222(50.8 \%)$, and RTA was $102(23.3 \%)$ with a rise in patients with RTA by $8.3 \%$.

\section{Injury severity}

Six studies provided complete neurological classification while the remaining 3 studies had classified ASIA B, C and $\mathrm{D}$ as incomplete neurology. One study used Frankel Grading to classify neurology. Seven hundred and thirtythree $(42 \%)$ patients in the included studies had incomplete neurology followed by $636(36.3 \%)$ patients with ASIA/ Frankel A neurology. (Table 3)

\section{Level of injury}

Most common level of injury included in all the studies was cervical (667) followed by lumbar (592) and thoracic (469).

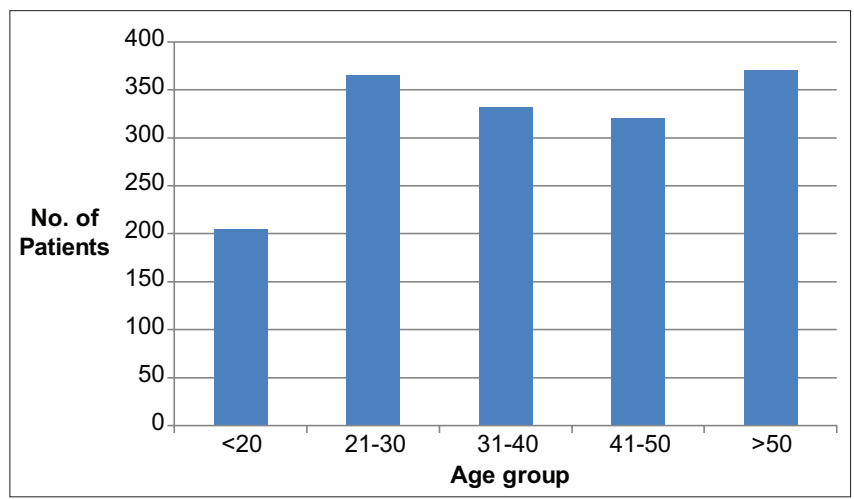

Figure 2: Age-wise classification of patients

\begin{tabular}{|c|c|c|c|c|c|}
\hline \multirow[t]{2}{*}{ Study } & \multicolumn{5}{|c|}{ Etiology } \\
\hline & Fall & RTA & Farm & Burial & Others \\
\hline Bajracharya et al., $2007^{13}$ & 538 & 116 & 72 & 0 & 170 \\
\hline Scovil et al., $2012^{19}$ & 31 & 1 & 0 & 0 & 5 \\
\hline Shrestha et al., $2013^{16}$ & 260 & 71 & 0 & 30 & 20 \\
\hline Devkota et al., $2013^{20}$ & 26 & 15 & 0 & 0 & 4 \\
\hline Groves et al., $2017^{14}$ & 19 & 0 & 0 & 98 & 0 \\
\hline Munakomi et al., $2017^{15}$ & 67 & 82 & 4 & 0 & 10 \\
\hline Dhakal et al., $2018^{17}$ & 84 & 7 & 0 & 0 & 0 \\
\hline Dhakal et al., $2019^{18}$ & 24 & 5 & 0 & 0 & 1 \\
\hline Kafle et al., $2019^{21}$ & 28 & 8 & 0 & 0 & 0 \\
\hline
\end{tabular}

But two literatures included only cervical injuries in their study $^{15,18}$ (Table 4).

\section{Arrival to hospital}

Only two of the included studies ${ }^{17,18}$ mentioned the duration of trauma to hospital arrival. Of the total 121 patients in those studies, $62 \%$ arrived within 2 days followed by $29 \%$ within 3 days to 7 days, and the remaining $9 \%$ patients arrived after 7 days of trauma.

\begin{tabular}{|c|c|c|c|c|c|c|}
\hline \multirow[t]{2}{*}{ Study } & \multicolumn{6}{|c|}{ ASIA } \\
\hline & $A$ & B & C & D & Incomplete & $E$ \\
\hline $\begin{array}{l}\text { Bajracharya } \\
\text { et al., } 2007^{13}\end{array}$ & 302 & 52 & 164 & 139 & 355 & 239 \\
\hline $\begin{array}{l}\text { Shrestha et al., } \\
2013^{16}\end{array}$ & 213 & 37 & 41 & 35 & 113 & 17 \\
\hline $\begin{array}{l}\text { Scovil et al., } \\
2012^{19}\end{array}$ & 22 & ---- & --- & ---- & 14 & 0 \\
\hline $\begin{array}{l}\text { Dhakal et al., } \\
2018^{17}\end{array}$ & 27 & ---- & ---- & ---- & 32 & 32 \\
\hline $\begin{array}{l}\text { Groves et al., } \\
2017^{14}\end{array}$ & 40 & 10 & 20 & 41 & 71 & 1 \\
\hline $\begin{array}{l}\text { Munakomi et al., } \\
2017^{15}\end{array}$ & 13 & 2 & 41 & 37 & 80 & 70 \\
\hline $\begin{array}{l}\text { Dhakal et al., } \\
2019^{18}\end{array}$ & 7 & ---- & --- & ---- & 18 & 5 \\
\hline $\begin{array}{l}\text { Kafle et al., } \\
2019^{21}\end{array}$ & 9 & 8 & 15 & 4 & 27 & 0 \\
\hline
\end{tabular}

\begin{tabular}{lcccccc} 
& \multicolumn{8}{c}{ Frankel } \\
\hline & A & B & C & D & Incomplete & E \\
\hline $\begin{array}{l}\text { Devkota et al., } \\
2013^{20}\end{array}$ & 3 & 3 & 11 & 9 & 23 & 19 \\
Total & 636 & & & & 733 & 383 \\
\hline
\end{tabular}

Table 4: Level of injury in $\mathrm{SCl}$ patients of Nepal

\begin{tabular}{|c|c|c|c|c|c|c|}
\hline \multirow[t]{2}{*}{ Study } & \multicolumn{6}{|c|}{ Level of injury } \\
\hline & $\begin{array}{l}\text { Cer- } \\
\text { vical }\end{array}$ & $\begin{array}{l}\text { Tho- } \\
\text { racic }\end{array}$ & $\begin{array}{l}\text { Lum- } \\
\text { bar }\end{array}$ & $\begin{array}{c}T / L \\
\text { junction }\end{array}$ & Sacral & $\begin{array}{c}\text { SCl } \\
\text { WORA }\end{array}$ \\
\hline $\begin{array}{l}\text { Bajracharya } \\
\text { et al., } 2007^{13}\end{array}$ & 358 & 171 & 331 & ------ & 9 & 27 \\
\hline $\begin{array}{l}\text { Scovil et al., } \\
2012^{19}\end{array}$ & 8 & 17 & 12 & ------- & 0 & 0 \\
\hline $\begin{array}{l}\text { Shrestha et al., } \\
2013^{16}\end{array}$ & 68 & 188 & 113 & ------ & 12 & 0 \\
\hline $\begin{array}{l}\text { Devkota et al., } \\
2013^{20}\end{array}$ & 8 & 12 & 25 & ------ & 0 & 0 \\
\hline $\begin{array}{l}\text { Groves et al., } \\
2017^{14}\end{array}$ & 8 & 44 & 56 & ------- & 1 & 0 \\
\hline $\begin{array}{l}\text { Munakomi } \\
\text { et al., } 2017^{15}\end{array}$ & 163 & 0 & 0 & -----' & 0 & 0 \\
\hline $\begin{array}{l}\text { Dhakal et al., } \\
2018^{17}\end{array}$ & 0 & 34 & 47 & 10 & 0 & 0 \\
\hline $\begin{array}{l}\text { Dhakal et al., } \\
2019^{18}\end{array}$ & 30 & 0 & 0 & $\cdots$ & 0 & 0 \\
\hline $\begin{array}{l}\text { Kafle et al., } \\
2019^{21}\end{array}$ & 24 & 3 & 8 & ------ & 0 & 0 \\
\hline Total & 667 & 469 & 592 & 10 & 22 & 27 \\
\hline
\end{tabular}




\section{Treatment modality}

All but one study ${ }^{19}$ mentioned about the treatment modality. Out of 1749 patients in these studies, 1081 $(61.8 \%)$ were managed conservatively while remaining 668 patients $(38.2 \%)$ underwent surgical intervention.

Comparing the studies before and after 2017, a significant shift to surgical management in recent years was observed. Only $25.4 \%$ of 1312 patients were managed surgically in the studies before 2017 - Bajracharya et al. ${ }^{13}$ Shrestha et al. ${ }^{16}$ and Devkota et al. ${ }^{20}$ But, in the studies after 2017 which included a total of 437 patients, ${ }^{14,15,17,18,21}$ the share of surgically managed patients was found to be $76.7 \%$.

Only four studies have mentioned improvement in neurology by one ASIA grade following the treatment. The number of patients with improvement of neurology by one grade was $15(33 \%)$ in the study by Devkota et al, ${ }^{20}$ $60(36.8 \%)$ in the study by Munakomi et al, ${ }^{15} 16(17.6 \%)$ and $14(46.7 \%)$ in two separate studies by Dhakal et al ${ }^{17,18}$ with a cumulative total patients to improve by one ASIA grade being 105 (32\%) in all four studies.

\section{Mortality}

Mortality data have been reported in very limited studies, and the data showed large variance. Munakomi et al., ${ }^{15}$ showed an overall mortality of $1.98 \%$ among prospectively studied cohort group of 163 cervical spine injury cases. In another prospective study, ${ }^{19}$ mortality after rehabilitation, however, was reported high $(24.32 \%)$.

\section{DISCUSSION}

Only nine epidemiological studies in SCI in Nepal till date, and no studies from the western part of the country indicate the scanty nature of investigation done in this topic. This worrying reality is intensified by the fact that the available studies have failed to use standardized pro forma to collect demographic information: multiple categories are used to collect data in terms of demography - some articles have provided region/district-specific incidence data - making the task of calculating incidence rate of SCI in Nepal implausible. Further, marked differences in the category such as age group, location of residence and etiology have made the analysis of data more problematic.

Higher incidence of SCI among male population (73\%), which is similar to the other studies from developed countries $^{22,23}$ as well, may be due to the male members being major responsible person to perform physically strenuous work in Nepalese society. Due to the nature of their work, they are at higher risk of fall from trees and house roofs.
Furthermore, women in developing countries like Nepal are more engaged in home-based activities, which may have diminished their risk of developing an $\mathrm{SCI}^{24}$ from fall related injuries.

The composite mean age of patients in the included studies is 40 years. Evaluating the age distribution, all age groups are almost equally affected by SCI with age $>50$ years being most commonly involved; it is contrary to other studies where majority of patients are of younger age group. ${ }^{8,22,25}$ The possible explanation for higher incidence of SCI in older age group might be the involvement of older individuals in potentially dangerous activities due to lesser number of younger population in rural Nepal as a result of migration. ${ }^{26,27}$

Pooled data captured in the review shows composite mean of fall as the principal cause of SCI (60\%). This result, compared to the calculation by Hamid et al $(75 \%),{ }^{28}$ is slightly lesser. Climbing trees to gather fodder for cattle is still a common practice in rural Nepal which explains higher incidence of fall injury. Another reason might be the terrain of the country - the northern part has hills and mountains, covering $77 \%$ of the total land leading to higher incidence of fall from cliffs and RTA. ${ }^{29}$ Other findings related to etiology do not vary much from earlier studies. ${ }^{30-33}$ Road traffic accident is the second highest etiology in many reports (composite mean as 17\%), the highest in one reviewed study ${ }^{15}$ and there is an increase in SCI caused by RTA in recent years by $8.3 \%(15 \%$ SCI patients due to RTA in the studies before 2017 compared to $23.3 \%$ SCI patients due to RTA in the studies in and after 2017); but it might not be enough to generalize that ranking of RTA etiology in Nepal will stand at the top, as reported in the studies from developed countries. $8,28,34,35$ However, the figure amply demands appropriate measures to reduce RTA. The study showing burial as the major etiology of $\mathrm{SCI}^{14}$ was the one done in post-earthquake 2015 in a rehabilitation centre in Kavre, Nepal.

Six hundred and thirty-six (36.3\%) patients with complete neurological deficiency signify the burden of SCI in Nepal. This figure is higher as compared to a study done in China $(25.2 \%)^{36}$ but lesser than the figures in Nigeria $(53 \%)^{37}$ and India $(71 \%) . .^{38}$ AIS A patients take up the major health resources for treatment and rehabilitation, therefore, measures in decreasing AIS A patient is of utmost importance.

Cervical injury is the most common level of injury (37.4\%) in the pooled data of all studies. Similar finding is seen in the studies done in other countries. ${ }^{39-42}$ Unique anatomy and high flexibility of cervical spine may be the reason to make cervical region more susceptible to injuries. ${ }^{43,44}$ 
Delayed access to hospital for treatment is another major observation from the review that demands further discussion (38\% patients arriving at the hospital after 48 hours of trauma). ${ }^{17}$ Unlike the studies in western countries where delay is due to treatment of other associated injuries in referring hospital and late diagnosis, ${ }^{45}$ the studies in Nepal have not explained the causes. To speculate, the cause of delay can be difficult terrain, lack of proper transportation, proximity to hospital facility and financial constraints.

There is an increasing trend for surgical management of spinal cord injury patients in recent years in Nepal. This is explained by an increase in the number of centers dealing with spinal injuries and also due to subsequent increase in skilled spine surgeons in Nepal in recent years. Furthermore, Ministry of Health and Population (MoHP) announced financial support of NPR one hundred thousand to the patient with spinal injury in $2014,{ }^{46}$ which must have an incremental effect in surgically managed patients with spinal injuries in recent years.

Only two studies included in the study have mentioned about the mortality rate ranging from $1.98 \%{ }^{15}$ to $24.32 \% .{ }^{19}$ The figure at the highest end is higher than many other studies outside Nepal: $10.25 \%$ in two institutions of America, ${ }^{47} 19 \%$ in the Department of Orthopaedic Surgery, Yokohama City University, Japan, ${ }^{48}$ and $20 \%$ in Spinal Cord Injury Centre in Western Denmark. ${ }^{49}$ Nevertheless, the rate at lower end is significantly low which demands further explication. Lower hospital death rate might be due to the tendency of the family to request for early discharge from hospital, thinking that treating further would not improve the condition of patients.

Further, financial limitations also could have obliged the families for early withdrawal from hospital treatment. Mortality being a matter of grave concern demands prospective longitudinal studies to find the gravity of death issue among SCI patients. Also, cross sectional large population based studies are required to validate the finding, and subsequently plan to address the concerns related to community rehabilitation.

\section{CONCLUSION}

Heterogeneity in the reports of demographic characteristics of SCI patients, particularly the location of residence, age group and etiology made comprehensive study and comparisons difficult. The number of epidemiological studies regarding SCI in Nepal is scanty and there are no studies from western part of the country. Males are still predominantly involved in SCI, and fall injury is the most common etiology though RTA is on the rise in recent years. An increasing acceptance to surgery as a mode of treatment is suggestive of availability of qualified surgeons, state of art technologies and favorable national policies for spinal cord injured patients.

Understanding epidemiology of SCI can contribute not only in defining risk groups for prevention and in managing health care system but also in providing comparative indicators that may inform interventions for prevention, health policy and resource management.

\section{RECOMMENDATIONS}

Standardized data collection formats are mandatory to facilitate globally usable epidemiological as well as clinical data as recommended by many previous studies. ${ }^{50} \mathrm{It}$ is a high time to start national spine registry in major tertiary care centers from all parts of Nepal for evaluating incidence, prevalence and other epidemiological parameters of spinal cord injury patients. Also, our focus on the etiology of SCI suggested that efforts should be made in preventing fall from heights and reducing road traffic accidents.

\section{ABBREVIATIONS}

AIS: ASIA injury severity; ASIA: American spine injury association; SCI: Spinal cord injury; SPSS - statistical package for social sciences

\section{Consent for publication \\ Not applicable.}

\section{Competing interests}

The authors declare that they have no competing interests.

\section{REFERENCES}

1. Hartkopp A, Brønnum-Hansen $H$, Seidenschnur AM and Biering-Sørensen F. Survival and cause of death after traumatic spinal cord injury. A long-term epidemiological survey from Denmark. Spinal cord. 1997;35(2):76-85.

https://doi.org/10.1038/sj.sc.3100351

2. Kang $\mathrm{Y}$, Ding $\mathrm{H}$, Zhou HX, Wei ZJ, Liu L, PanDY, et al. Epidemiology of worldwide spinal cord injury: a literature review. Journal of Neurorestoratology. 2017;6:1-9. https://doi.org/10.2147/JN.S143236

3. Thietje R and Hirschfeld S. Epidemiology of spinal cord injury. Neurological aspects of spinal cord injury: Springer; 2017:3-17. https://doi.org/10.1007/978-3-319-46293-6_1

4. Singh A, Tetreault L, Kalsi-Ryan S, Nouri A and Fehlings MG. Global prevalence and incidence of traumatic spinal cord injury. Clinical epidemiology. 2014;6:309. https://doi.org/10.2147/CLEP.S68889

5. Knútsdóttir $\mathrm{S}$, Thorisdottir $\mathrm{H}$, Sigvaldason $\mathrm{K}$, Jonsson Jr $\mathrm{H}$, 
Björnsson A and Ingvarsson P. Epidemiology of traumatic spinal cord injuries in Iceland from 1975 to 2009. Spinal cord. 2012;50(2):123.

https://doi.org/10.1038/sc.2011.105

6. New PW, Baxter D, Farry A and Noonan VK. Estimating the incidence and prevalence of traumatic spinal cord injury in Australia. Archives of physical medicine and rehabilitation. 2015;96(1):76-83.

https://doi.org/10.1016/j.apmr.2014.08.013

7. Srivastava RN, Singh A, Garg RK, Agarwal A and Raj S. Epidemiology of Traumatic Spinal Cord Injury: A SAARC Perspective. International Journal of Molecular Biology \& Biochemistry. 2015;3(1):9-22.

8. Rahimi-Movaghar V, Sayyah MK, Akbari H, Khorramirouz R, Rasouli MR, Moradi-Lakeh M, et al. Epidemiology of traumatic spinal cord injury in developing countries: a systematic review. Neuroepidemiology. 2013;41(2):65-85.

https://doi.org/10.1159/000350710

9. McCammon JR and Ethans K. Spinal cord injury in Manitoba: a provincial epidemiological study. The journal of spinal cord medicine. 2011;34(1):6-10.

https://doi.org/10.1179/107902610X12923394765733

10. Wyndaele $\mathrm{M}$ and Wyndaele J-J. Incidence, prevalence and epidemiology of spinal cord injury: what learns a worldwide literature survey? Spinal cord. 2006;44(9):523-529. https://doi.org/10.1038/sj.sc.3101893

11. Lakhey S, Jha N, Shrestha B and Niraula S. Aetioepidemiological profile of spinal injury patients in Eastern Nepal. Tropical doctor. 2005;35(4):231-233.

https://doi.org/10.1258/004947505774938756

12. Shrestha D, Garg M, Singh G, Singh M and Sharma U. Cervical spine injuries in a teaching hospital of eastern region of Nepal: a clinico-epidemiological study. JNMA; journal of the Nepal Medical Association. 2007;46(167):107-111.

13. Bajracharya S, Singh M, Singh GK and Shrestha BP. Clinicoepidemiological study of spinal injuries in a predominantly rural population of eastern Nepal: A 10 years' analysis. Indian journal of orthopaedics. 2007;41(4):286.

https://doi.org/10.4103/0019-5413.36988

14. Groves C, Poudel M, Baniya M, Rana C and House D. Descriptive study of earthquake-related spinal cord injury in Nepal. Spinal Cord. 2017;55(7):705-710.

https://doi.org/10.1038/sc.2017.25

15. Munakomi S, Bhattarai B and Cherian I. Prospective observational research on the clinical profile and outcome analysis among a cohort of patients sustaining traumatic cervical spine and cord injury in a peripheral tertiary spine care centre in Nepal. F1000 Research. 2017;6.

https://doi.org/10.12688/f1000research.12911.1

16. Shrestha $P$, Shrestha $S$ and Shrestha R. Retrospective study of spinal cord injury patients admitted to spinal injury rehabilitation centre, Sanga, Banepa, Nepal. Nepal Med Coll J. 2014;16(2-4):169-172.

17. Dhakal GR, Paudel S, Dhungana S, Gurung $G$ and Kawaguchi $Y$. Epidemiological Characteristics of Dorsal and Lumbar Spine Trauma Presenting to a Trauma Hospital in Kathmandu, Nepal: Formulation of a National Spine Policy. Spine Surgery and Related Research. 2018:2017-0087.

https://doi.org/10.22603/ssrr.2017-0087

18. Dhakal GR, Bhandari R, Dhungana S, Poudel S, Gurung G, Kawaguchi $Y$, et al. Review of Subaxial Cervical Spine Injuries Presenting to a Tertiary-Level Hospital in Nepal: Challenges in Surgical Management in a Third World Scenario. Global spine journal. 2019;9(7):713-716.

https://doi.org/10.1177/2192568219833049

19. Scovil CY, Ranabhat MK, Craighead IB and Wee J. Followup study of spinal cord injured patients after discharge from inpatient rehabilitation in Nepal in 2007. Spinal Cord. 2012;50(3):232-237.

https://doi.org/10.1038/sc.2011.119

20. Devkota P, Manandhar $\mathrm{H}$ and Khadka P. Spinal Injuries in a Tertiary Care Referral Center of Western Nepal. Nepal Journal of Medical Sciences. 2013;2(2):156-159. https://doi.org/10.3126/njms.v2i2.8967

21. Kafle P, Khanal B, Yadav DK, Poudel D and Cherian I. Spinal cord injury, Clinical Profile and its Management at Tertiary Care Center in Nepal. Journal of Nobel Medical College. 2019;8(1):16-21.

https://doi.org/10.3126/jonmc.v8i1.24450

22. Chamberlain JD, Deriaz $\mathrm{O}$, Hund-Georgiadis $M$, Meier $\mathrm{S}$, Scheel-Sailer A, Schubert $M$, et al. Epidemiology and contemporary risk profile of traumatic spinal cord injury in Switzerland. Injury epidemiology. 2015;2(1):28. https://doi.org/10.1186/s40621-015-0061-4

23. DeVivo MJ. Epidemiology of traumatic spinal cord injury: trends and future implications. Spinal cord. 2012;50(5):365-372. https://doi.org/10.1038/sc.2011.178

24. Otom A, Doughan A, Kawar J and Hattar E. Traumatic spinal cord injuries in Jordan-an epidemiological study. Spinal cord. 1997;35(4):253-255. https://doi.org/10.1038/sj.sc.3100402

25. Chiu WT, Lin HC, Lam C, Chu SF, Chiang YH and Tsai SH. Epidemiology of traumatic spinal cord injury: comparisons between developed and developing countries. Asia Pacific Journal of Public Health. 2010;22(1):9-18. https://doi.org/10.1177/1010539509355470

26. Ghimire S, Singh DR, Nath D, Jeffers EM and Kaphle M. Adult children's migration and well-being of left behind Nepalese elderly parents. Journal of epidemiology and global health. 2018;8(3):154-161.

https://doi.org/10.1016/j.jegh.2018.07.004

27. Gautam TR. Migration and the problem of old age people in Nepal. Dhaulagiri Journal of Sociology and Anthropology. 2008;2:145-160.

https://doi.org/10.3126/dsaj.v2i0.1361

28. Hamid R, Averbeck MA, Chiang H, Garcia A, Al Mousa RY, Oh SJ, et al. Epidemiology and pathophysiology of neurogenic bladder after spinal cord injury. World journal of urology. 2018;36(10):1517-1527.

https://doi.org/10.1007/s00345-018-2301-z

29. Poudel M, Bhandari R, Uprety S, Baral D and Gupta PP. Epidemiological study of road traffic accident cases in emergency department of tertiary care centre of Eastern Nepal. Asian Pacific Journal of Health Sciences. 2018;5(2):179-182. https://doi.org/10.21276/apjhs.2018.5.2.34

30. Rathore MFA, Hanif S, Farooq F, Ahmad N and Mansoor SN. Traumatic spinal cord injuries at a tertiary care rehabilitation institute in Pakistan. JPMA. The Journal of the Pakistan Medical Association. 2008;58(2):53.

31. Zhou $Y$, Wang $X B$, Kan SL, Ning GZ, Li YL, Yang B, et al. Traumatic spinal cord injury in Tianjin, China: a single-center report of 354 cases. Spinal Cord. 2016;54(9):670-674. https://doi.org/10.1038/sc.2015.173

32. Montoto-Marqués A, Ferreiro-Velasco M, Salvador-De La Barrera S, Balboa-Barreiro V, Rodriguez-Sotillo A and 
Meijide-Failde R. Epidemiology of traumatic spinal cord injury in Galicia, Spain: trends over a 20 -year period. Spinal Cord. 2017;55(6):588-594.

https://doi.org/10.1038/sc.2017.13

33. Smith E, Finn S and Fitzpatrick P. Epidemiology of pediatric traumatic and acquired nontraumatic spinal cord injury in Ireland. Topics in spinal cord injury rehabilitation. 2017;23(3):279-284. https://doi.org/10.1310/sci16-00029

34. Chen $Y, H e Y$ and DeVivo MJ. Changing demographics and injury profile of new traumatic spinal cord injuries in the United States, 1972-2014. Archives of physical medicine and rehabilitation. 2016;97(10):1610-1619.

https://doi.org/10.1016/j.apmr.2016.03.017

35. Bellucci CHS, de Castro Filho JE, Gomes CM, de Bessa Jr J, Battistella LR, de Souza R, et al. Contemporary trends in the epidemiology of traumatic spinal cord injury: changes in age and etiology. Neuroepidemiology. 2015;44(2):85-90.

https://doi.org/10.1159/000371519

36. Ning G, Yu T, Feng S, Zhou XH, Ban DX, Liu Y, et al. Epidemiology of traumatic spinal cord injury in Tianjin, China. Spinal cord. 2011;49(3):386-390.

https://doi.org/10.1038/sc.2010.130

37. Nwankwo OE and Uche EO. Epidemiological and treatment profiles of spinal cord injury in southeast Nigeria. Spinal Cord. 2013;51(6):448-452.

https://doi.org/10.1038/sc.2013.10

38. Chhabra $\mathrm{H}$ and Arora $\mathrm{M}$. Demographic profile of traumatic spinal cord injuries admitted at Indian Spinal Injuries Centre with special emphasis on mode of injury: a retrospective study. Spinal Cord. 2012;50(10):745-754. https://doi.org/10.1038/sc.2012.45

39. Tafida MA, Wagatsuma $\mathrm{Y}, \mathrm{Ma}$ E, Mizutani $T$ and Abe T. Descriptive epidemiology of traumatic spinal injury in Japan. Journal of orthopaedic science. 2018;23(2):273-276. https://doi.org/10.1016/j.jos.2017.10.013

40. Birua GJS, Munda VS and Murmu NN. Epidemiology of spinal injury in north East India: a retrospective study. Asian journal of neurosurgery. 2018;13(4):1084.

https://doi.org/10.4103/ajns.AJNS_196_17
41. Knútsdóttir $S$, Thorisdottir $H$, Sigvaldason $K$, Jónsson $H$, Björnsson $A$ and Ingvarsson P. Epidemiology of traumatic spinal cord injuries in Iceland from 1975 to 2009. Spinal cord. 2012;50(2):123-126.

https://doi.org/10.1038/sc.2011.105

42. Islam M, Hafez M and Akter M. Characterization of spinal cord lesion in patients attending a specialized rehabilitation center in Bangladesh. Spinal cord. 2011;49(7):783-786. https://doi.org/10.1038/sc.2011.36

43. Torretti JA and Sengupta DK. Cervical spine trauma. Indian journal of orthopaedics. 2007;41(4):255. https://doi.org/10.4103/0019-5413.36985

44. Torlincasi AM and Waseem M. Cervical Injury. StatPearls [Internet]: StatPearls Publishing; 2019.

45. Amin A, Bernard J, Nadarajah R, Davies N, Gow F and Tucker S. Spinal injuries admitted to a specialist centre over a 5-year period: a study to evaluate delayed admission. Spinal cord. 2005;43(7):434-437.

https://doi.org/10.1038/sj.sc.3101734

46. Services. DoH. Medical Treatment of Deprived Citizens. 2014; https://www.mohp.gov.np/eng/program/medical-treatmentdeprived-citizen. Accessed 29 June, 2020, 2020.

47. Garshick E, Kelley A, Cohen SA, Garrison A, Tun CG, Gagnon D, et al. A prospective assessment of mortality in chronic spinal cord injury. Spinal cord. 2005;43(7):408-416. https://doi.org/10.1038/sj.sc.3101729

48. Higashi T, Eguchi H, Wakayama Y, Sumi M and Saito T. Risk factors associated with mortality after traumatic cervical spinal cord injury. Ota International. 2018;1(1):e003. https://doi.org/10.1097/OI9.0000000000000003

49. Noe B, Stapelfeldt C, Parner E and Mikkelsen E. Survival after traumatic spinal cord injury in Denmark: a hospital-based study among patients injured in 1990-2012. Spinal cord. 2017; 55(4):373-377. https://doi.org/10.1038/sc.2016.154

50. Lee B, Cripps R, Fitzharris M and Wing P. The global map for traumatic spinal cord injury epidemiology: update 2011, global incidence rate. Spinal cord. 2014;52(2):110.

https://doi.org/10.1038/sc.2012.158

\section{Author's contributions:}

BP-Contributed to the conception and design of the study, development of data extraction forms, search strategy, manuscript writing and final review of the manuscript; KA-Contributed to the methodological design, manuscript writing as well as critical revision, and final review of the manuscript; DS- Contributed to the critical revision and final review of the manuscript; BP- Undertakes the responsibility for the accuracy of the manuscript. All authors read and approved the

final manuscript.

\section{Work attributed to:}

Department of Orthopedics and Traumatology, Dhulikhel Hospital, Kathmandu University Hospital, Dhulikhel, Nepal.

Orcid ID:

Dr Bikash Parajuli - (i) https://orcid.org/0000-0001-5449-418X

Dr Khagendra Acharya - (1) https://orcid.org/0000-0002-4212-4779

Sources of support: University Grants Commission, Nepal, Funding ID: FRG-75/76-HS-16

Conflicts of Interests: None. 